\title{
课程思政在 “无机化学”课程教学中的探索
}

汪羽领, 马荔*, 谢少艾, 张卫, 魏霄, 尹屹梅, 陈虹锦

上海交通大学化学化工学院, 上海 200240

摘要: 课程思政是新时代教育改革背景下提出的创新教育理念, 教师不再是单纯的知识传播者, 还应在教学过程中 注重学生思想道德、思维品质等各方面能力素质的全面发展。无机化学是化学、化工、材料、环境、生物、药学等 化学近源专业面向大一新生所开设的专业基础课程, 在新形势下课程内容和思政教育融合并举, 在无机化学课程中 进行课程思政教学改革具有重要意义。

关键词: 无机化学; 课程思政; 科学思维; 价值引领; 全面发展

中图分类号: G64; O6

\section{Exploration on "Course Ideology and Politics" in Teaching of Inorganic Chemistry}

\author{
Yuling Wang, Li Ma *, Shaoai Xie, Wei Zhang, Xiao Wei, Yimei Yin, Hongjin Chen \\ College of Chemistry and Chemical Engineering, Shanghai Jiao Tong University, Shanghai 200240, China.
}

\begin{abstract}
Course ideology and politics is an innovative educational concept proposed under the background of education reform in the new era. Teachers are no longer merely disseminators of knowledge, but should pay more attention to the comprehensive development of students' ideological morality, thinking quality and other abilities in the process of teaching. Inorganic chemistry is a basic course for freshmen of chemistry, chemical engineering, materials, environment, biology, pharmacy and other related majors. Under the new situation, curriculum content as well as ideological and political education are integrated simultaneously, and is of great significance to the ideological and political teaching reform in the course of inorganic chemistry.
\end{abstract}

Key Words: Inorganic chemistry; Course ideology and politics; Scientific thought; Value guidance; Comprehensive development

2016年12月 8日, 习近平总书记在全国高校思想政治工作会议上强调指出 ${ }^{[1]}$ : “要用好课堂教学 这个主渠道, 思想政治理论课要坚持在改进中加强, 提升思想政治教育亲和力和针对性, 满足学生 成长发展需求和期待, 其他各门课都要守好一段渠、种好责任田, 使各类课程与思想政治理论课同 向同行, 形成协同效应。” 高校阶段是青少年学生思维模式升华的重要时期, 因此思想政治与价值取 向培养尤为重要。课程思政教学改革由上海市率先发起, 经历了教学规范、理论探索、改革深化、 全面推广 4 个阶段, 现在全国范围内部署推广 “课程思政”, 在明确的时代背景下进行课程思政教学 改革具有切实的必要性。课程思政是高校完善全员全程全方位育人的重要抓手, 它以科学有效的教

收稿: 2021-01-24; 录用: 2021-02-23; 网络发表: 2021-02-26

“通讯作者, Email: mali@sjtu.edu.cn

基金资助：上海市课程思政领航计划重点改革项目(ZXDF602041/002) 
育教学原则指导育人实践, 提升育人效果 ${ }^{[2,3]}$ 。

目前对课程思政的诠释有三维向度。宏观层面, 课程思政作为一种教育观, 反映的是教育整体 性哲学观点, 是教育主体基于人的全面发展目标下而进行的教育价值选择与追求。科学的教育理念 是教育价值的思想凝结, 是教育规律的折射, 对教育改革与发展具有规范性和导向性作用。课程思 政作为一种教育理念, 指引高等教育溯本追源、回归初心, 把人的全面发展、整体教育理念体现在 课程教学的主渠道中; 中观层面, 课程思政是一种课程观, 是教育价值实现的载体。课程思政虽然 并不是具体的课程形态, 但作为一种课程观念, 可以落实教育价值理念, 实现教学中知识传授与价 值导引的融合; 微观层面, 课程思政是一种教学方法论, 是教育价值实现的方式手段。从古至今, 教育形式变化、教育内容更迭、教育方式革新, 但教育却仍有着亘古不变的价值追求, 以真善美合 一的育人目标注重对学生德行生活与自觉文明生活的引导, 形成对人内在精神与灵魂的教育关 切 ${ }^{[2,4]}$ 。

\section{1 无机化学课程与课程思政双重教学目标}

“无机化学 1 ” 是我校化学、化工、药学、农学、环境、生物、海洋化学等专业的第一门专业基 础课。课程主要内容是向大一新生全面介绍化学学科分支、化学基本知识与理论、现代化学研究的 前沿课题等, 具有承前启后的作用。通过学习让学生掌握无机化学的基本概念、原理及物质结构的 基础理论; 掌握化学平衡理论, 结合各种平衡体系的计算结果来处理化工生产中的简单问题; 熟悉 氧化还原反应与电化学的理论, 结合电极电势的计算, 正确选择化工生产所需要的溶剂、反应物、 催化剂等。为后续专业课程提供必备的理论基础知识, 了解化学的独特思维方式, 激发学生对化学 类学科的兴趣, 培养学生正确的学习方法、逻辑思维和创新理念, 以及树立学生将知识转化为生产 力服务于社会的信念 ${ }^{[3]}$ 。在无机化学课程中融入思政元素并不难, 难的是如何在授课过程中把控节 奏, 将思政元素与知识传授巧妙融合, 春风化雨、润物无声地发挥课程育人的重要作用 ${ }^{\left[{ }^{[}-8\right]}$ 。

作为上海市课程思政领航学院和领航课程, 上海交通大学化学化工学院无机化学教学团队编写 新的教学大纲, 大纲中涵盖课程思政的案例和映射点, 以期达到自然渗透学科教学、追求潜移默化、 知微见著的效果。

在传统的掌握基本原理、物质结构和水溶液平衡这三大知识板块的专业技能和实践应用技能的 基础之上, 增设课程思政教学目标, 主要包括: (1) 明确培养目标, 在传授知识中实现价值引领, 除 了增强学生的学习兴趣, 进一步帮助学生在进行能力培养的同时树立正确的价值观和民族自豪感; (2) 更新传统的教学模式, 进一步提高学生自主学习的积极性, 增强学生认识世界和改造世界的能 力, 帮助学生实现人生价值; (3) 将知识点和思想政治观点相融合, 通过同步的化学实验和大作业的 形式促进学生认真思考、积极参与讨论, 增强学生对专业的认同感, 帮助学生规划职业目标, 从而 服务国家与社会。以上目标旨在实现无机化学课程教学与思政课程教学目标同向同行, 从而实现课 程育人的总体目标。

无机化学课程核心内容的思政元素主要从家国情怀、社会责任、人文教育、文化传承等多个方 面展开, 选好案例, 事半功倍。主要案例设计见表1, 章节顺序依据教材是吉林大学、武汉大学、南 开大学出版的无机化学(第4版)上册。

\section{2 课程思政在教学实践中的探索}

\section{1 通过学习老一辈科学家事迹为例, 增强民族自信心}

科学无国界, 但科学家有祖国, 科学家胸怀国家和民族。在教学中讲述我国老一辈科学家满怀 “以天下为己任” 投身民族振兴伟业中的先进事迹, 让学生了解我国老一辈科学家在艰苦岁月中力 学笃行、无私奉献、报效祖国的崇高精神, 激发学生爱国情、强国志、报国行的情怀与信念。 
表1 无机化学思政元素教学内容设计

\begin{tabular}{|c|c|c|c|}
\hline & 章节 & 内容 & 课程思政讨论点 \\
\hline \multirow{3}{*}{\multicolumn{2}{|c|}{ 绪论 }} & 1.1 化学发展历史与人类社会发展的关系 & 1. 化学史 $\rightarrow$ 体现科学发展观 \\
\hline & & 1.2 无机化学的继往开来 & 2. 徐光宪校友开创稀土萃取体系案例 $\rightarrow$ 勇攀科学高峰的勇气, 激 \\
\hline & & 1.3 研究化学的方法 & 发学生科技报国的家国情怀和使命担当 \\
\hline 第一章 & 化学基础知识 & 1.1 气体 & 1. 热力学相关定律 $\rightarrow$ 宏观世界方法论 \\
\hline \multirow[t]{3}{*}{ 第二章 } & 化学热力学初步 & 2.1 热力学第一定律 & 2. 热力学定律 $\rightarrow$ 第一次/第二次工业革命 $\rightarrow$ 社会发展的科学推动 \\
\hline & & 2.2 热化学 & 力 \\
\hline & & 2.3 化学反应的方向 & \\
\hline \multirow[t]{7}{*}{ 第三章 } & 化学反应速率 & 3.1 反应速率的定义 & 1. 反应速率理论 $\rightarrow$ 综合考虑影响事物发展的各种因素 $\rightarrow$ 抓住问 \\
\hline & & 3.2 反应速率和浓度的关系 & 题的主要矛盾。 \\
\hline & & 3.3 反应机理 & 2. 催化反应原理 $\rightarrow$ 事物发展必经的过渡态(活化能) $\rightarrow$ 目标实现的 \\
\hline & & 3.4 反应浓度与时间的关系 & “过犹不及”和“协同发展” \\
\hline & & 3.5 反应速率理论简介 & \\
\hline & & 3.6 温度对反应速率的影响 & \\
\hline & & 3.7 催化剂简介 & \\
\hline \multirow[t]{4}{*}{ 第四章 } & 化学平衡 & 4.1 化学平衡状态 & 1. $\mathrm{CO}_{2}$ 的排放和利用 $\rightarrow$ 平衡的辩证思想 $\rightarrow$ 地球命运共同体的和谐 \\
\hline & & 4.2 化学反应进行的方向 & 发展 \\
\hline & & 4.3 标准平衡常数吉布斯自由能的关系 & 2. 平衡移动原理 $\rightarrow$ 个人成长阶段和父母的关系 $\rightarrow$ 人类学/社会学 \\
\hline & & 4.4 化学平衡的移动 & 中的平衡关系 \\
\hline 第五章 & 原子结构和元素周 & 5.1 近代原子结构理论的确立 & 1. 原子结构理论 $\rightarrow$ 微观世界方法论 $\rightarrow$ 宏观世界和微观世界的区 \\
\hline \multirow[t]{5}{*}{ 期律 } & & 5.2 微观粒子运动的特殊性 & 别与联系 \\
\hline & & 5.3 核外电子运动的描述 & 2. 门捷列夫和元素周期表 $\rightarrow$ 马克思哲学基本原理与认识 $\rightarrow$ 理论 \\
\hline & & 5.4 核外电子的排布 & 和实验结合, 实践是检验真理的标准 \\
\hline & & 5.5 元素周期表 & 3. 元素周期表有尽头吗? $\rightarrow$ 科研态度: 大胆预测、谨慎求证 \\
\hline & & 5.6 元素性质的周期性 & \\
\hline 第六章 & 分子结构与共价键 & 6.1 价键理论 & 1. 价键理论发展过程 $\rightarrow$ 发现问题解决问题的经验规律 \\
\hline \multirow[t]{4}{*}{ 理论 } & & 6.2 杂化轨道理论 & 2. $\mathrm{C}_{60}$ 的发现和制备 $\rightarrow$ 知识互补、经验互补、优势互补在科学进步 \\
\hline & & 6.3 价层电子对互斥理论 & 中的重要作用, 树立精诚合作的团队意识 \\
\hline & & 6.4 分子轨道理论 & 3. $\mathrm{CCS}$ 最新报道 ${ }^{[9]} \rightarrow$ 传统价层电子对互斥理论的补充 $\rightarrow$ 科学质疑 \\
\hline & & & 精神 \\
\hline \multirow[t]{6}{*}{ 第七章 } & 晶体结构 & 1.3 固体和晶体 & 1. 晶体结构 $\rightarrow$ 表象和内在的关联 \\
\hline & & 7.1 分子晶体和分子间作用力 & 2. 离子键和离子极化理论 $\rightarrow$ 事物的绝对性和相对性 \\
\hline & & 7.2 离子晶体和离子键 & 3. 金刚石和石墨 $\rightarrow$ 结构本质与相互转化 $\rightarrow$ 宏观辨识与微观解析 \\
\hline & & 7.3 离子极化 & \\
\hline & & 7.4 金属晶体和金属键 & \\
\hline & & 7.5 原子晶体和混合晶体 & \\
\hline \multirow[t]{3}{*}{ 第八章 } & 酸碱平衡 & 8.1 弱酸和弱碱的解离平衡 & 1. 酸碱体质案例 $\rightarrow$ 酸碱平衡和缓冲作用原理 $\rightarrow$ 辩证分析问题 \\
\hline & & 8.2 盐的水解 & 2. 侯氏制碱法案例 $\rightarrow$ 老一辈科学家不断探索艰苦创业 $\rightarrow$ 家国情 \\
\hline & & 8.3 酸碱理论 & 怀和使命担当 \\
\hline
\end{tabular}


大学 化 学 Univ. Chem. 2021, 36 (3), 2101047 (4 of 6)

(续表1)

\begin{tabular}{|c|c|c|}
\hline 章节 & 内容 & 课程思政讨论点 \\
\hline \multirow[t]{3}{*}{ 第九章 沉淀溶解平衡 } & 9.1 溶度积常数 & 1. 钡餐案例和人体内的重金属元素 $\rightarrow$ 沉淀溶解平衡原理 $\rightarrow$ 生活/ \\
\hline & 9.2 沉淀生成的计算与应用 & 生命中的化学 \\
\hline & 9.3 沉淀的溶解和转化 & 2. 土壤污染案例 $\rightarrow$ 环境化学 $\rightarrow$ 化学改变生活、创造生活 \\
\hline \multirow[t]{5}{*}{ 第十章 氧化还原平衡 } & 10.1 氧化还原反应和原电池 & 1. 新能源汽车行业的崛起和发展 $\rightarrow$ 电化学原理的应用 $\rightarrow$ 科学与 \\
\hline & 10.2 电池反应的热力学 & 技术的互相促进 \\
\hline & 10.3 影响电极电势的因素 & 2. 工业和建筑业中的钢铁腐蚀 $\rightarrow$ 解决现代化建设高速发展的基 \\
\hline & 10.4 图解法讨论电极电势 & 本问题 $\rightarrow$ 国家需求和专业认同感 \\
\hline & 10.5 氧化还原反应的应用 & \\
\hline \multirow[t]{4}{*}{ 第十一章 配位平衡 } & 11.1 配合物基本概念 & 1. Werner的 “配位键理论” 获1913年诺贝尔化学奖的于 $\rightarrow$ 新老知 \\
\hline & 11.2 配位化合物的价键理论 & 识体系的碰撞和争锋 $\rightarrow$ 实验科学的事实依据 $\rightarrow$ 勇于突破的科研精 \\
\hline & 11.3 配位化合物的晶体场理论 & 神 \\
\hline & 11.4 配位化合物的稳定性 & $\begin{array}{l}\text { 2. 生命体系的重要配合物 } \rightarrow \text { 各种平衡的融合运用 } \rightarrow \text { 化学、生物、 } \\
\text { 生命等学科的交叉融合, 共同发展 }\end{array}$ \\
\hline
\end{tabular}

在原子结构章节讲到徐光宪规则, 以徐光宪先生的事例激发学生的国家荣誉感和专业认同感。 “中国稀土之父” 徐光宪院士，1944年毕业于交通大学化学系，1951年3月, 获美国哥伦比亚大学博 士学位。同年他毅然回到了满目疮痍、百废待兴的新中国, 投身祖国的建设大业。20世纪70年代, 他 负责攻克 “稀土元素分离” 这个世界性难题。经过无数次的计算和实验终于开创出 “串级萃取理论”, 一举攻克稀土中分离难度最大的镨、钕两种元素的分离技术, 纯度达到 $99.99 \%$, 并把这项技术完美 地应用于大规模的生产实践 $[10]$ 。从此, 中国作为稀土资源大国, 不再只是以 “猪肉价” 出售稀土原 矿, 而是一跃而成为稀土加工大国, 至今仍占据着世界稀土生产加工的制高点。大家要铭记徐光宪 先生毅然归国的满腔热忱和爱国情怀, 弘扬徐光宪在化学领域为国家强盛、民族复兴和教育事业所 做的杰出贡献, 激励莘莘学子 “饮水思源, 爱国荣校” , 彰显 “与祖国同向同行” 的价值文化。

在酸碱平衡章节, 以近代化学史上有名的侯氏制碱法为例, 介绍侯德榜先生在20世纪20-60年代 为中国化学工业的发展做出的突出贡献。侯德榜是我国化学工业的奠基人、纯碱工业的创始人。他 发明的 “侯氏制碱法” 使合成氨和制碱两大生产体系有机地结合起来, 提高了食盐利用率, 缩短了 生产流程, 减少了对环境的污染, 降低了纯碱的成本, 在人类化学工业史上写下了光辉的一页。在 授课过程中, 引发学生思考, 如果几十年前的科学问题摆在当今大学生面前, 我们能否解决? 能不 能拿出更好的方案? 如果不能, 是不是愧对时代, 还有什么理由不好好学习?

\section{2 以我国化学工业前沿领域为例, 增强民族自豪感}

我国化学工业从弱到强, 综合国力日益强盛, 坚定了我们的道路自信与制度自信。教学中介绍 我国化学工业前沿领域, 以此为思想政治教育融入点, 增强学生对我国化学工业的自信心与自豪感, 激励学生立志肩负民族复兴的时代重任。

$\mathrm{CO}_{2}$ 的排放及其具有吸热和隔热的功能使得全球温室效应日益严峻, 由于 $\mathrm{CO}_{2}$ 的惰性, 如何实现 在温和条件下的化学转化是一个极具挑战性的科学问题。丁奎岭院士作为有机化学家, 长期关注 $\mathrm{CO}_{2}$ 资源化利用问题, 基于多年来在催化氢化方面的研究积累, 通过发展新型金属有机催化剂, 实现了 在温和条件下将 $\mathrm{CO}_{2}$ 作为 “碳资源”, 通过化学转化制备出甲醇、 DMF等常用化工原料, 为二氧化 碳的资源化再利用提供了新的方法和思路 ${ }^{[11,12]}$ 。此类走在世界前沿、代表中国科技崛起的重大科技 成果的介绍, 不仅让学生深刻理解在化学平衡和化学反应速率中催化剂的作用, 也起到激发学生民 族自豪感, 增强学生理想信念的作用。 


\section{3 根据身边科学家事例, 弘扬社会主义核心价值观, 加强环保意识}

习近平总书记强调 ${ }^{[13]}$ : “生态环境保护是功在当代、利在千秋的事业。要清醒认识保护生态环 境、治理环境污染的紧迫性和艰巨性, 清醒认识加强生态文明建设的重要性和必要性, 以对人民群 众、对子孙后代高度负责的态度和责任, 真正下决心把环境污染治理好、把生态环境建设好, 努力 走向社会主义生态文明新时代, 为人民创造良好生产生活环境。” 随着我国工业化的快速发展, 20 世纪90年代开始, 长期污染导致湖水富营养化, 云南洱海两次大规模暴发藻华, 水质急速下降。上 海交通大学环境科学与工程学院孔海南教授和他的团队, 十余年默默扎根污染水域一线, 用坚守和 奉献, 让洱海重现往日 “母亲湖” 的风采 ${ }^{[14]}$ 。上海交通大学 “老人与海” 的故事激励和引导学生把 个人理想融入祖国发展伟业, 为中华民族伟大复兴和 “中国梦” 贡献智慧和力量, 加强自己对社会 主义核心价值观的理解和认识。

\section{4 以化学实验为载体, 激发学生科技报国使命担当, 结合生活生产实例}

金属材料腐蚀与防护已经成为一门重要的学科。它涉及到我国经济发展过程中重要的经济领域, 因此获得正确的、有效的防腐技术, 可以遏制或防止腐蚀的产生, 可以最大限度地减少由金属材料 腐蚀造成的经济损失和其他危害。

随着我国工业化进程的加快，腐蚀防护已成为关联国计民生、经济建设持续发展的重要技术之 一。就我国而言, 西气东输、青藏铁路、高速铁路、核电站、海洋采油等重大工程建设都给腐蚀防 护带来新的挑战。统计结果表明, 被腐蚀的钢铁约占我国钢铁年产量的十分之一, 因金属腐蚀而造 成的损失占到国内生产总值的 $3 \%$ 左右 ${ }^{[15-17]}$ 。通过理论知识的传授, 结合实验课程中的 “金属吸氧腐 蚀、析氢腐蚀与防护” 的具体实验, 让学生通过实验探讨金属腐蚀的原理和防止钢铁腐蚀的方法, 并了解钢铁使用中防护的重要性, 通过分析我国钢铁生产技术及目前我国防腐技术发展状况, 端正 学生的学术价值观, 激发学生科技报国的家国情怀和使命担当。

将无机化学理论与化学实验课程有机结合起来, 使学生建立起化学理论基础和实验的依存关系, 以及灵活的化学思维方法, 了解实验在化学学科发展中的重要作用, 进一步明确化学对于生活的重要 性; 了解批判性思维在学科发展中的重要作用和实践创新能力对学科发展的重要性; 进一步养成刻 苦务实、努力拼搏、敢为人先、体魄强壮、诚实守信的人格。

\section{5 以大作业为载体, 锻炼学生查找、整合信息能力}

在无机化学教学过程中实施课程思政, 教师不仅仅采取讲授的方式, 更多的采取互动式、启发 式、讨论式等教学模式。例如提出一些 “浅谈化学热力学的发展及其意义” “缓冲体系的稳定性及 深度思考” “温室气体 $\mathrm{CO}_{2}$ 的转化利用” “思辨之火Werner配位键理论” “酸碱平衡与侯氏制碱法” 等具有代表性的课题, 指导学生查阅文献资料, 充分利用上海交通大学图书馆数据库等信息资源进 行学习, 引导学生查找资源以及整合信息进行讨论, 通过讨论提高学生对思想政治的认识, 增强典 范教育的效果。大部分同学完成得非常好, 格式规范、逻辑强、参考资料齐全、PPT制作精美, 同时 还有自己的思考与见解。

结合化学热力学这一章节的内容, 梁同学介绍了一直富有争议的 “永动机” 问题。他通过PPT的 形式, 先给大家介绍 “永动机” 的定义及名称的由来; 再深入浅出地介绍永动机的发展历程及各个 时期的结构特点; 最后进行总结, 深度阐述永动机的历史意义及其永远不可能被制成的原因。追寻 永动机失败的历史, 可以给我们两点启示: (1) 失败的经历也有积极的科学研究价值, 永动机的种种 设计方案的失败, 引起了人们的反思, 启发了能量转化和守恒的思想, 成为能量转化和守恒定律建 立的重要思考线索之一; (2) 人类利用自然, 必须遵循自然规律。道法自然, 天道酬勤, 勤奋学习, 以建设祖国为理想和目标，激发学生科技报国的家国情怀和使命担当。

结合化学平衡这一章的内容, 段同学用平衡移动的原理来讨论个人成长不同阶段和父母的关系, 将理学的严谨与人情的温度紧密地结合在一起。正如一个反应会达到一定的限度, 一个故事、一段 人生也会有终止。但平衡时那宏观上的静止, 隐藏不了微观下粒子们依旧进行碰撞反应的实质; 一 
如在漫漫岁月里, 我们之间经历过剧烈的反应而最后归于平静, 和家人逐渐心照不宣不再提起那句 “我爱你” , 但是从深层次依旧可以感受到脉脉温情。化学虽为理学学科, 但也和世间百态、人情 世故一样具有冷暖苦乐。

结合配位键理论这一章内容, 时同学通过了解维尔纳提出配位键理论背后的故事, 分析维尔纳 的科学研究精神, 并进一步探讨怎样的科学研究才是科研的根本。该同学深刻地体会到 “探索求真、 理性实证、质疑创新、实践独立” 这十六个字在维尔纳身上一一体现。从中也指导自己对待学习和 今后的人生的信条是付出实践、努力求索、刻苦钻研、求真求实、理性实证、不受外界干扰、不受 浮世影响、一心一意地追求真理。

\section{3 结语}

著名化学家戴安邦教授曾说过 “化学教学既传授化学知识和技术, 更训练科学方法和思维, 还 培养科学精神和品德” [18]。作为无机化学教学团队, 目前在课程思政建设中只是做了初步尝试, 我 们还需要深入挖掘无机化学课程内容的思政元素, 厘清课程内容和思政内容的本质联系, 而不仅仅 局限于表面文章, 把富有时代感的思政内容与课程内容相融合。同时要端正授课教师对于思政教育 的态度，提高授课教师的思想政治水平，采用集体备课的形式统一思政教育内容、思政教育方式方 法。直于课堂授课的学时有限, 可充分利用校相关社团活动、“化学节”、小组讨论等多种形式, 使教师讲授和学生自我教育有机结合, 将“课程思政”的目标与大学新生的学习生活相融合贯通。 让大学新生在获得知识的同时, 潜移默化地接受思政教育, 实现立德树人、润物细无声, 有利于树 立正确的价值观、人生观和世界观。

\section{参 考 文 献}

[1] 新华网. 习近平出席全国高校思想政治工作会议并讲话. [2016-12-08]. http://www.xinhuanet.com//politics/2016-12/08/c_1120083340.htm

[2] 张兴海, 李珊珊. 中国高等教育, 2020, No. 13, 7 .

[3] 郭丽, 周志强, 韩福芹, 曹晶晶. 教育进展, 2019, 9 (5), 602.

[4] 张弛, 宋来. 思想教育研究, 2020, No. 2, 93 .

[5] 季桂娟, 李政, 周屹博, 许文辉. 当代化工研究, 2020, No. 10, 116.

[6] 刘志莲, 崔玉, 刘思全, 杨小风, 王守锋. 大学化学, 2020, 35 (9), 31.

[7] 刘天府. 大学化学, 2020, 35 (8), 44.

[8] 展鹏, 蒋小飞, 王艺铭, 兰共德, 刘新泳. 大学化学, 2019, 34 (11), 61.

[9] Wu, J.; Jin, B.; Wang, X.; Ding, Y. Y.; Wang, X. L.; Tang, D. D.; Li, X. H.; Shu, J.; Li, D. S.; Lin, Q. P.; et al. CCS Chem. 2020, $2,2548$.

[10] 肖丹. 中国科技奖励, 2020, No. 7, 44 .

[11] Zhang, L.; Han, Z. B.; Zhao, X. Y.; Wang, Z.; Ding, K. L. Angew. Chem. Int. Ed. 2015, 54, 6186.

[12] Han, Z. B.; Rong, L. C.; Wu, J.; Zhang, L.; Wang, Z.; Ding, K. L. Angew. Chem. Int. Ed. 2012, 51, 13041.

[13] 人民网. 习近平: 生态环境保护是功在当代、利在千秋的事业. [2015-08-05].

http://cpc.people.com.cn/xuexi/n/2015/0805/c385474-27412488.html

[14] 上海交通大学新闻学术网. 孔海南: 交大版“老人与海”的故事: 把论文写在祖国大地上. [2018-11-19]. https://news.sjtu.edu.cn/agfd/20181125/90541.html

[15] 马厚义, 崔聪颖, 陈婷. 电化学, 2011, 17 (5), 288.

[16] 黄国亮, 薛蔓凌, 字映竹. 世界有色金属, 2018, No. 3, 217.

[17] 马荔, 陈虹锦. 无机与分析化学实验. 北京: 化学工业出版社, 2019: 117-119.

[18] 季桂娟, 李政, 周屹博, 许文辉. 当代化工研究, 2020, No. 10, 116. 